\title{
Thymoma and systemic lupus erythematosus
}

\author{
J OSEPH F. SIMEONE, THERESA M C L OUD, \\ CHARLES E. PUT MAN, a nd JOH MAR SH \\ Departments of Diagnostic, Radiology, Internal Medicine, and Pharmacology,
Yale University School of Medicine, USA
}

\begin{abstract}
Simeone, J. F., McLoud, Theresa, Putman, C. E., and Marsh, J. (1975). Thorax, 30, 697-700. Thymoma and systemic lupus erythematosus. The simultaneous occurrence of a thymoma and systemic lupus erythematosus (SLE) is reported. Disease states associated with thymoma are reviewed and the possible immunological basis for this spectrum of diseases is discussed. The role of angiography in the diagnosis of thymic tumours is described.
\end{abstract}

This is the report of a case of thymoma associated with systemic lupus erythematosus. Although the association of these two pathological states is rare (Larsson, 1963; MacKechnie, Squires, and Platts, 1973), they have been found together in association with other diseases (Clinical Pathologic Conference, 1973; Funkhouser, 1961; Galbraith, Summerskill, and Murray, 1964; Kough and Barnes, 1964; Montes, Carter, and Moreland, 1968; Peterson and Lund, 1969; Singh, 1969).

In December 1972, the patient developed pains in the knees and metacarpophalangeal and proximal interphalangeal joints and also a Raynaud phenomenon. The ESR was elevated at $55 \mathrm{~mm}$ in 1 hour and the anti-nuclear factor was 1:1024. LE preparation showed one cell to be positive. A repeat ANF at a later time was 1:4096. The patient responded well to a brief course of prednisone but in September 1973 presented at another hospital with chest pain and a pericardial friction rub. A chest radiograph at that time revealed a right pleural effusion and a large mediastinal mass (Figs. 1 and 2). A mediastinoscopy was performed and a biopsy specimen showed normal lymphoid and involuted thymic tissue.

In November 1973, chest radiographs showed that the mediastinal mass was smaller. The ANF was positive to a titre of $1: 256$ and the LE preparation was positive. Arteriography via a right internal mammary artery in December 1973 demonstrated a vascular tumour (Fig. 3). Exploratory thoracotomy in January 1974 revealed a large, firm, lobular mass occupying the right lobe of the thymus which was enlarged to $8 \times 7 \times 5 \mathrm{~cm}$. The tumour did not involve other structures. A total thymectomy was performed and histological examination showed an epithelioid

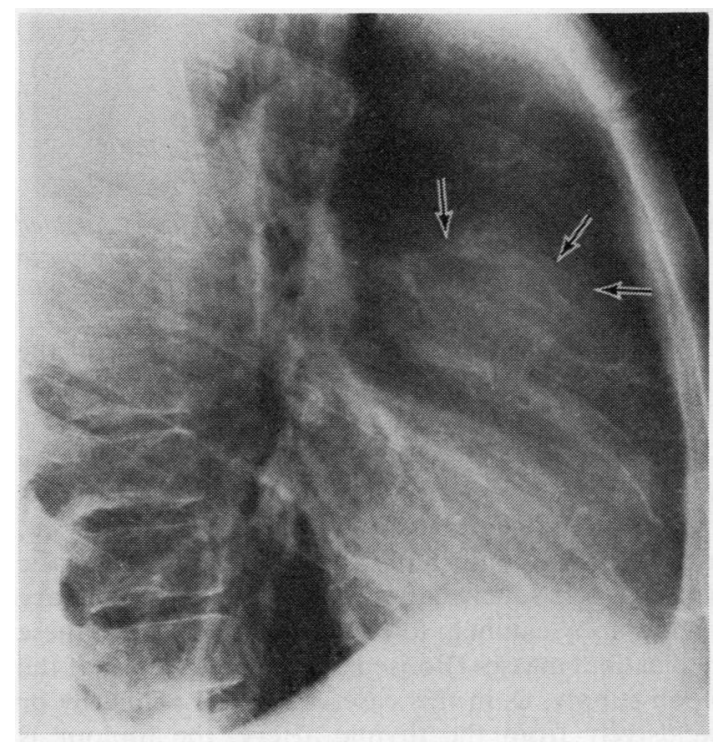

FIG. 1. Lateral chest radiograph shows a mass of soft tissue density in the anterior mediastinum (arrows).

and lymphoid thymoma (Fig. 4). Many cystic and necrotic areas were present and the tumour was observed to invade the capsule of the thymus as well as surrounding normal thymic tissue. Lymph nodes at some distance from the tumour were not involved microscopically. In January 1974, radiation therapy was given to a total dose of 4800 rads.

Removal of the thymoma temporarily reduced the clinical and laboratory manifestations of SLE. At the time of discharge, the patient was free of previously described symptoms, and no LE cells were found but 


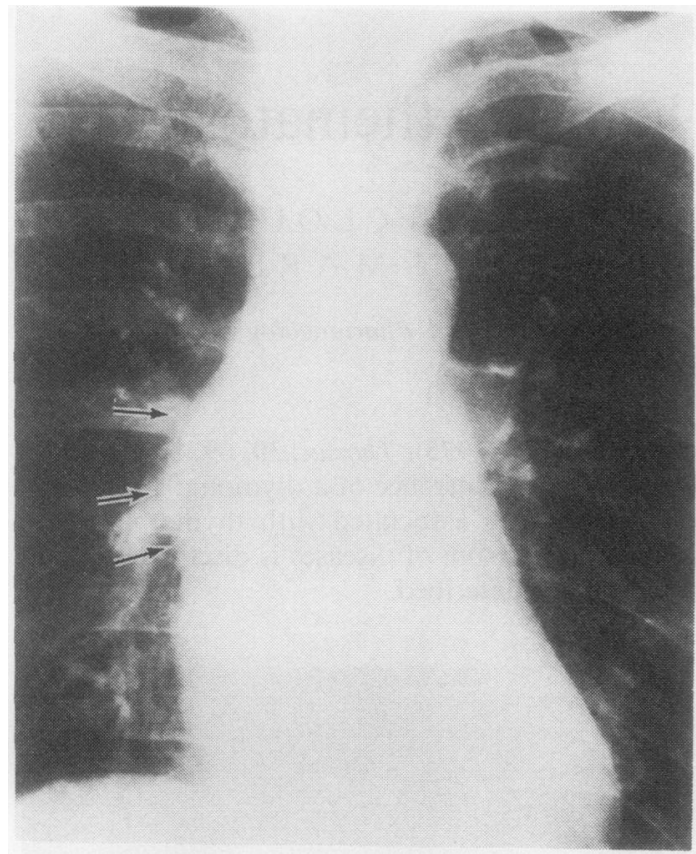

FIG. 2. PA chest radiograph shows a smooth right-sided mediastinal mass in the region of the ascending aorta (arrows).

the ANF was positive to a titre of $1: 1024$, and the DNA binding capacity was $53 \%$.

\section{DISCUSSION}

Masses occurring in the anterior mediastinum include thymoma, teratoma, dermoid cyst, aneurysm, substernal thyroid, lymph nodes, and metastatic neoplasms. Subclavian and internal mammary angiography can help to clarify and distinguish these mediastinal masses (Boijsen and Reuter, 1966). If the blood supply, as in this case, is derived primarily or exclusively from the thymic artery, the tumour is probably a thymoma. Although it is difficult to distinguish benign from malignant thymomas, the former is suggested by an absence of tumour vessels and a smooth margin to the mass. In contrast, a dermoid cyst is usually a totally avascular lesion. Substernal thyroids are very vascular masses which are supplied by an enlarged inferior thyroid artery. Many small tortuous tumour vessels arising from the internal mammary artery characterize metastatic deposits. Mediastinal angiography, in this case, was of value not only in establishing a diagnosis but also in determining the presence and extent of the tumour's blood supply. However, its obvious limitation in distinguishing benign from malignant thymomas should be noted.
The patient fulfils the majority of the generally accepted criteria for systemic lupus erythematosus which include an ANF titre of more than 1:64, pleurisy, pericarditis, LE cells, arthralgia, and Raynaud's phenomenon (Wolf, Gokcen, and Good, 1963).

Within the past few years the number of different $\vec{\circ}$ diseases found in association with thymoma has been steadily increasing (Rubin, 1964). The earliest and most firmly established connections include myasthenia gravis (Castleman, 1955), erythroid aplasia (Chalmers and Reheimer, 1954), and agammaglobulinaemia (MacLeary, Zak, and Varco, 1956). Other associations are numerous and include the

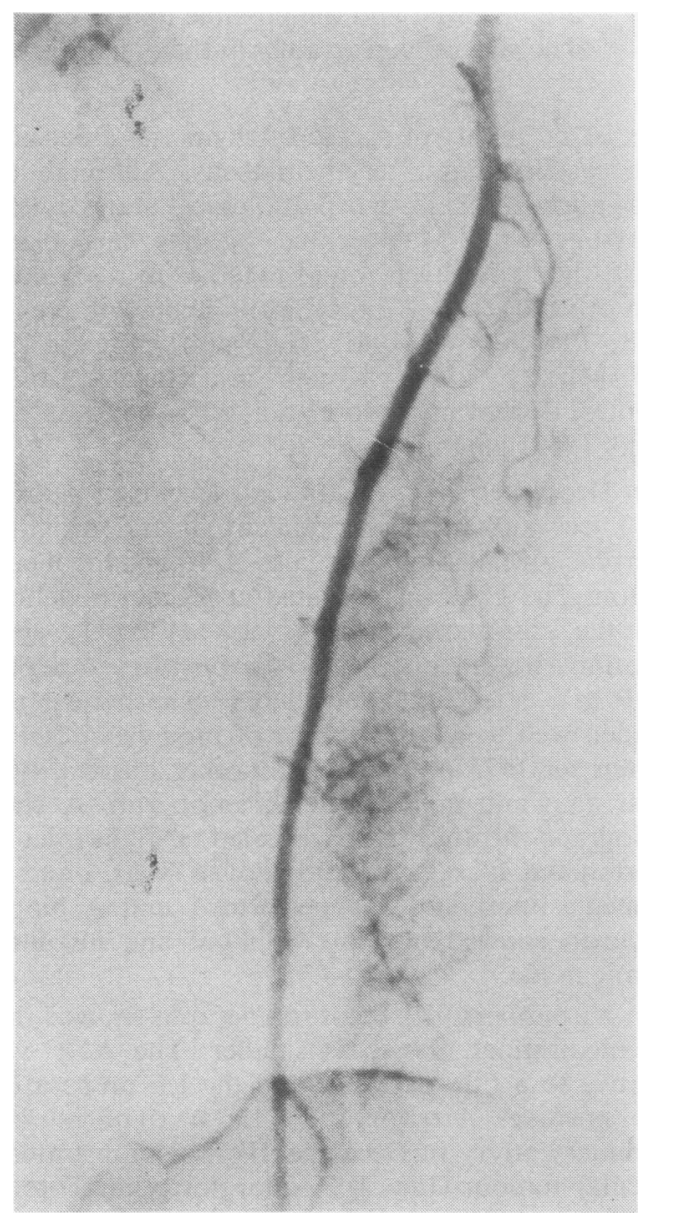

FIG. 3. Subtraction technique. Angiogram following internal mammary injection shows tortuous branches of an enlarged thymic artery within the mass. A parenchymal blush is seen extending from the superior mediastinum down to the level of the diaphragm. 


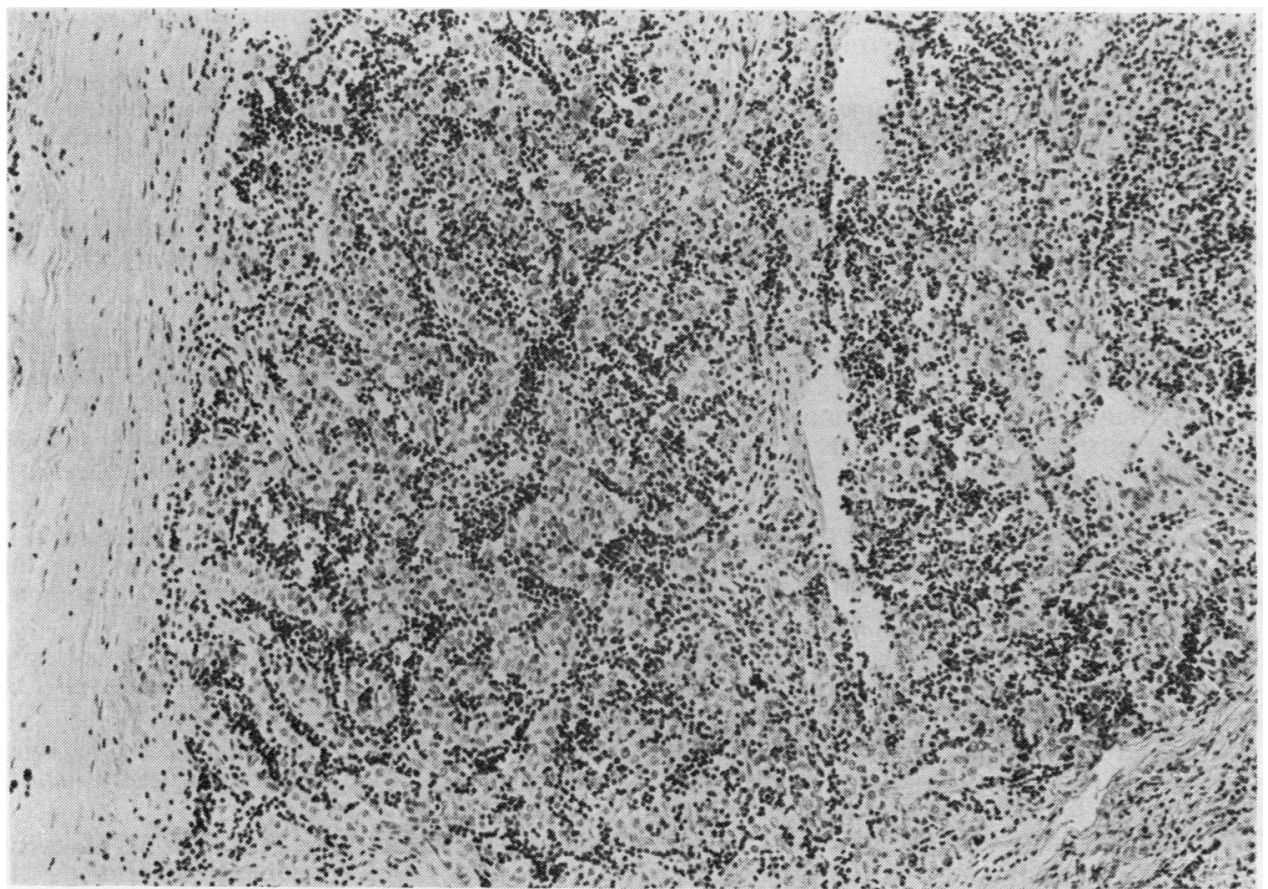

FIG. 4. Thymoma with two distinct cell types-small, dark lymphoid cells and larger, pale epithelial cells. There is lobulation by proliferating connective tissue at the left margin and lower right (Haematoxylin and eosin $\times 77$ ).

following: hypoplasia of other marrow elements (Havard and Scott, 1960), carditis (Funkhouser, 1961), positive Coombs' test (Jahsman, Monto and Rebuck, 1962), Cushing's syndrome (Pimstone, Uys, and Vogelpoel, 1972), Hashimoto's thyroiditis (Dawson, 1972), pemphigus (Lynfield, Pertschuk, and Zimmerman, 1973), candidiasis (Stillman and Baer, 1973), myositis and myopathy (Rubin, 1964), multiple myeloma (Lindstrom, Williams, and Brunning, 1968), leukaemia (Anderson and Henning, 1967), erythrocytosis (Lundstrom, 1970), and megaoesophagus (Demos, Yadusky, and Tinmes, 1966).

The association of thymoma and systemic lupus erythematosus remains to be explained. Bach (1974) has presented evidence to support the existence of a circulating thymic hormone and has noted that the level of this hormone is decreased in some immune deficient states and in patients with SLE. Disease in NZB mice (East, 1970), similar to human lupus erythematosus, is characterized by abnormalities in $T$ cells before autoimmune manifestations appear. Thymoma and SLE occurring in the same patient lends support to the hypothesis that the thymus gland is primarily responsible for the development and regulation of auto antibodies.
A consistent relation between thymoma and SLE has not been proven, but accumulating data would support more than a casual relationship between these two relatively rare disease states. Improvement in our patient's clinical condition following thymectomy might suggest that a thymic tumour should be excluded in patients with SLE refractory to the usual therapeutic measures.

\section{REFERENCES}

Anderson, V. and Henning, P. (1967). Thymoma and acute leukemia. Acta Medica Scandinavica, 182, 581.

Bach, J. F. (1974). Le thymus, organ clef de l'immunité. La Nouvelle Présse Medicale, 3, 571.

Boijsen, E. and Reuter, S. (1966). Subclavian and internal mammary angiography in the evaluation of anterior mediastinal masses. American Journal of Radiology, 98, 447.

Castleman, B. (1955). Tumors of the thymic gland. In The Atlas of Tumor Pathology, Section 5, p. 19. The Armed Forces Institute of Pathology. Washington, D.C.

Chalmers, J. N. M. and Reheimer, K. (1954). Pure red cell anemia in patients with thymic tumors. British Medical Journal, 2, 1514.

Clinical Pathologic Conference (1973). New England Journal of Medicine, 288, 729. 
Dawson, M. A. (1972). Thymoma associated with pancytopenia and Hashimoto's thyroiditis. American Journal of Medicine, 52, 406.

Demos, N. J., Yadusky, R. J. and Tinmes, J. J. (1966). Thymoma associated with megaesophagus, a case report. Journal of Thoracic and Cardiovascular Surgery, 51, 708.

East, J. (1970). Immunopathology and neoplasms in New Zealand black (NZB) and SJL/J mice. Progress in Experimental Tumor Research, 13, 85.

Funkhouser, J. W. (1961). Thymoma associated with myocarditis and the LE phenomenon. New England Journal of Medicine, 34, 264.

Galbraith, R. F., Summerskill, W. H. J., and Murray, J. (1964). SLE, cirrhosis and ulcerative colitis after thymectomy for myasthenia gravis. New England Journal of Medicine, 270, 229.

Havard, C. W. and Scott, R. B. (1960). Thymic tumor and erythroblastic aplasia. British Journal of Haemotology, 6, 178.

Jahsman, D. P., Monto, R. W., and Rebuck, J. W. (1962). Erythroid hypoplastic anemia (erythroblastopenia) associated with benign thymoma. American Journal of Clinical Pathology, 38, 152.

Kough, R. H. and Barnes, W. T. (1964). Thymoma associated with erythroid aplasia, bullous skin eruption and the LE cell phenomenon, a report of a case. Annals of Internal Medicine, 61, 308.

Larsson, O. (1963). Thymoma and systemic lupus erythematosus in the same patient. Lancet, 2, 665.

Lindstrom, F. D., Williams, R. C., and Brunning, R. D. (1968). Thymoma associated with multiple myeloma. Archives of Internal Medicine, 122, 526.

Lundstrom, C. (1970). A case of thymoma in association with erythrocytosis. Acta Pathologica et Microbiologica Scandinavica, 80, 487 .

Lynfield, Y. L., Pertschuk, L. P., and Zimmerman, A. (1973). Pemphigus erythematosus provoked by allergic contact dermatitis. Occurrence many years after thymoma removal. Archives of Dermatology, $108,690$.

MacKechnie, H. L. N., Squires, A. H. and Platts, M. (1973). Thymoma, myasthenia gravis, erythroblastic anemia and SLE in one patient. Canadian Medical Association Journal, 109, 733.

MacLeary, L. D., Zak, S. J., and Varco, R. I. (1956). Thymic tumor and acquired agammaglobulinemia a clinical and experimental study of the immune response. Surgery, 40, 1010.

Montes, L. F., Carter, R. E., and Moreland, N. (1968) Generalized cutaneous candidiasis associated with diffuse myopathy and thymoma. Journal of the American Medical Association, 204, 351.

Peterson, P. and Lund, J. (1969). SLE following thymectomy for myasthenia gravis. Danish Medical Bulletin, 16, 179.

Pimstone, B. L., Uys, C. J. and Vogelpoel, L. (1972). Studies in a case of Cushing's syndrome due to an ACTH producing thymic tumor. American Journal of Medicine, 53, 521 .

Rubin, M. (1964). Clinical disorders associated with thymic tumors. Archives of Internal Medicine, 114, 389.

Singh, B. N. (1969). Thymoma presenting with polyserositis and the LE syndrome. Australian Annals of Medicine, 18, 55.

Stillman, M. A. and Baer, R. L. (1973). Mucocutaneous candidiasis and thymoma. Journal of the American Medical Association, 224, 628.

Wolf, J. K., Gokcen, M., and Good, R. A. (1963). Heredofamilial diseases of the mesenchymal tissues: clinical and laboratory study of one family. Journal of Laboratory and Clinical Medicine, 61, 230.

Requests for reprints to: Dr. C. G. Putman, Department of Radiology and Medicine, Yale University School of Medicine, 33 Cedar Street, New Haven, Connecticut, 05510, USA. 